\title{
DERLEME
}

\section{Hemşirelik Eğitiminde Hemşirelik Kuram ve Modellerinin Kullanılmasının Önemi}

$$
\text { Fahriye PAZARCIKCI }{ }^{1} \text {, Ayşe UÇAK }{ }^{2}
$$

\section{ÖZ}

Hemşirelik kuram ve modellerinin temel amacı, hemşirelik biliminin gelişmesini sağlamaktır. Hemşirelik eğitiminde kuram ve model kullanımı hemşirelerin ortak bir dile sahip olması noktasında oldukça önemlidir. Hemşirelik kuram ve modellerine temellendirilen hemşirelik eğitimi hemşirelik felsefesini anlayan, kendi rollerini benimseyen, bireyi bütüncül değerlendirebilen hemşireler yetiştirilmesini, eğitimin niteliğinin artmasını, bilgilerin daha kolay entegre edilmesi ve öğrenilmesini olanaklı kılacak, öğrenciye problem çözme becerisi kazandıracak ve hemşirelik bilgisini artıracaktır. Bu çalışma, hemşirelik kuram ve modellerinin hemşirelik eğitiminin nitelik ve standardizasyonunu artıracak, hemşirelik eğitiminde öğrencinin bilgisini geliştirebilmek ve ilerletebilmek için kullanabilecek metot ve yaklaşımlardan biri olduğunun önemine vurgu yapmak amacıyla yapılmıştır.

Anahtar Kelimeler: Hemşirelik Eğitimi; Hemşirelik Kuramı; Hemşirelik Modeli

\section{The Importance of Using Theories and Models of Nursing in Nursing Education Fahriye PAZARCIKCI ${ }^{1}$, Ayşe UÇAK ${ }^{2}$}

\begin{abstract}
The primary purpose of nursing theory and models is to ensure the development of nursing science. The use of theory and model in nursing education is very important for nurses to have a common language. Nursing education, which is based on nursing theories and models, understands the philosophy of nursing, adopts its own roles, can evaluate the individual as a whole, will enable the student to increase the quality of education, integrate and learn more easily, and will increase the nursing knowledge to the student. This study was carried out to emphasize the importance of nursing theories and models as one of the methods and approaches that will increase the quality and standardization of nursing education and that can be used to improve and advance the knowledge of the student in nursing education.
\end{abstract}

Keywords: Nursing Education; Nursing Model; Nursing Theory

\footnotetext{
${ }^{1}$ Süleyman Demirel Üniversitesi, Sağlık Bilimleri Fakültesi, Hemşirelik Bölümü, Isparta, Türkiye

${ }^{2}$ Mehmet Akif Ersoy Üniversitesi, Sosyal Bilimler Meslek Yüksekokulu, Burdur, Türkiye. Sorumlu Yazar: Fahriye PAZARCIKCI

E-posta adresi: fahriyecelikk@gmail.com_ＯRCID No: 0000-0002-3249-299X Gönderi Tarihi: 16.06 .2020 


\section{GíRiş}

Bilim ve teknolojideki ilerlemeler son yillarda sağlık bakım hizmetlerinde anlamlı bir değişime neden olmuştur (1). Ancak, sağlık bakım hizmetlerinde yaşanan bu değişim konusunda hemşirelik eğitimi beklenenden daha yavaş bir ilerleme göstermiştir (2). Bu sorun hemşire liderler, hemşirelik örgütleri ya da hemşirelik eğitiminden kendisini sorumlu hissedenler tarafından y1llardır tartışılmakta olup, istendik değişimin hemşirelik eğitimi, yönetimi ve uygulamalarındaki yenileşim hareketleri ile gerçekleşebileceği iddia edilmektedir $(2,3)$.

Hemşirelik eğitiminin niteliğini artırmak için literatürde heyecan oluşturan çeşitli kavramlardan sıklıkla söz edilmektedir. Probleme dayalı öğrenme, yaşam boyu öğrenme, toplum tabanl1 öğrenme, hemşirelikte bilişim, kanıta dayalı uygulamalar, kritik düşünme, kalite-performans iyileştirme, kültürler arası hemşirelik, hümanizm, empati, eleştirel düşünme bunlardan birkaçıdır $(2,4)$. Dahası, hemşirelik eğitim, öğretim ve uygulamalarının müfredatı için yeni kavramlar; örneğin hümanizm gibi sevgi temelli bakım uygulamaları, öğrenci ve öğretmenin sorumluluğu paylaştı̆̆ı, çeşitli öğrenme, bilme yolları üzerinde durulmaktadır. Çalışmalar, hemşirelik eğitiminde hemşirelik değerleri ve anlamlarının geliştirilmesi, multidisipliner ve disiplinler ötesi işbirliğgi, toplum tabanlı kişiler arası öğrenme kavramları, nüfus çeşitliliği, sağlığın teşviki ve sağlık bilişimine artan vurgu, sağlık ekonomisi, simülasyonun kullanımını, meslekler arası uzmanlık, eğitimsel işbirlikleri ve uzaktan eğitim, hızlandırılmış programlar, kavram tabanlı müfredat, sanal topluluklar, holistik bakım gibi kavramların daha fazla geliştirilmesi gerektiğine dikkat çekmektedir $(2,5,6)$. Ülkemizde ise hemşirelik eğitiminde birkaç model denenmiş olmasına rağmen (programa dayalı öğrenme, entegre uygulamalar) biyomedikal model çerçevesinde hemşirelik eğitiminin kurgulandığı görülmektedir (7). Oysaki daha 1950'li ve 1960'l1 yıllarda, tıbbi kavram ve sorunlardan çok, hemşirelik kavram ve sorunlarına odaklanılmasını sağlayacak bir hemşirelik eğitim programı oluşturulmasının gerekliliğinden, ancak bu şartlarda hemşireliğin görüş açısının yansıtılabileceğinden bahsedilmektedir (8). 
Barnum (9), hemşirelik eğitim müfredatının ders içerikleri ve eğitim yöntemlerinin muhakkak bir ya da birden fazla hemşirelik kuram ve modeline dayandırılması gerektiğini bildirmiştir. Literatürde hemşirelik eğitim ve uygulamalarında kullanılabilecek doğru ya da yanlış hemşirelik kuram ve modeli olmadığı vurgulanmaktadır. Hemşirelik eğitim ve uygulamaları için doğru olanın müfredatı modele dayandırmak olduğu vurgulanmakta, hemşirelik eğitim kurumlarının kendi hemşirelik felsefeleri doğrultusunda müfredatlarını geliştirmeleri ve böylece hemşirelik programının kavramsal veya organizasyonel yapısının hemşirelik felsefesini yansıtabileceği bildirilmektedir (2,5).

Hemşirelik kuram ve modellerine temellendirilen hemşirelik eğitimi, hemşirelik felsefesini anlayan, kendi rollerini benimseyen, bireyi bütüncül değerlendirebilen hemşireler yetiştirilmesini, eğitimin niteliğinin artmasını, bilgilerin daha kolay entegre edilmesi ve öğrenilmesini olanaklı kılacak, öğrenciye problem çözme becerisi kazandıracak ve bilgisini arttıracaktır $(1,2,7)$.

$\mathrm{Bu}$ çalışma, hemşirelik kuram ve modellerinin hemşirelik eğitiminde nitelik ve standardizasyonunu artıracak, hemşirelik eğitiminde öğrencinin bilgisini geliştirebilmek ve ilerletebilmek için kullanabilecek metot ve yaklaşımlardan biri olduğunun önemine vurgu yapmak amacıyla yapılmıştır.

\section{Hemşirelik Eğitiminde Kavramsal Çalışmalar}

Hemşirelik kuram ve modelleri, hemşirelik eğitim ve literatür yaşamına son 50 yılda büyük bir ivme kazandırmıştır. Hemşirelik tarihine bakıldığında formal eğitimin Florence Nigtingale ile başladığ ancak hastanelerde hekime bağımlı olarak yürütüldüğü görülmektedir (8).

Tarihsel süreç incelendiğinde hemşirelik eğitimindeki standardizasyonun 1930’lu yıllarda oluşmaya başladığı görülmektedir. Bu dönemde, hemşirelik eğitiminin üniversite düzeyinde verilmesi, hastanelerde hekimlere bağıml olmaktan çıkarılarak kendi meslek üyeleri tarafından verilmesi gerektiği tartışmaları başlamıştır. Aynı zamanda "hastalık merkezli bakım" yerini "hastalığı olan birey merkezli bakım" anlayışına birakmıştır $(1,7,10)$.

1950 ve 1960 'larda ise “Hemşirelik eğitimi nasıl olmalı? Nasıl bir müfredat uygulanmalı? Daha etkin bir hemşirelik bakımını nasıl verebiliriz?" 
tartışmaları sıkça yaşanmıştır (1). Meleis (8)'e göre bu dönem çeşitli müfredat ders programlarının denenmesi, öğretim elemanı ve yöneticilerin eğitimi, “İdeal hemşire nasıl yetiştirilir? Müfredat ders programları nasıl olmalı?” tartışmaları nedeniyle hemşirelik bakımının nasıl olması gerektiği konusunun unutulduğu ancak hemşirelik kuram ve modellerinin de gelişmesine olanak sağlayan bir dönem olmuştur. Bu sırada okullarda hemşirelik müfredat ders programları geliştirilirken usta-çırak bağlantısı ile karakterize eğitim geleneğinin birakılması üzerinde durulmuştur (1). Sonuç olarak 1950'lerde ve 1960’larda hemşirelik eğitiminde, hastalık ve ilaç tedavisi odaklı olan biyomedikal model kullanılmaya başlanmıştır $(1,7,8)$.

1972 yılında okul müfredatlarının temelini oluşturan akreditasyon kriterleri gündeme gelmiş ve Ulusal Hemşirelik Birliğine (International Council of Nursing-NLN) bağlı fakültelerin okul müfredatları oluşturulmuştur. $\mathrm{Bu}$ sayede, hemşirelik kavram ve teorilerinde önemli bir gelişme sağlanmıştır. NLN, hemşirelik programı hedefleri, içeriği, seçimi, kurs düzenleri gibi devletin müfredat aktivitelerini planlanmasında felsefi bir yaklaşım getirmiştir. NLN her fakültenin bir ya da karma bir hemşirelik teorisi seçmesini ve programlarını ona göre uyarlamasını önermiştir (3).

\section{Hemşirelik Eğitiminde Hemşirelik Kuram ve Modelleri Nasıl Kullanılır?}

Hemşirelik eğitiminde hemşirelik kavram ve modelleri iki yolla kullanılmaktadır. Birincisi hemşirelik kavram ve modelleri hemşirelik müfredat programının yapı ve içeriğini, organizasyonunu tanımlamak için kullanılabilmektedir. İkincisi, öğretim elemanları tarafından öğrencilerin eğitimi için kullanılan öğretim süreci stratejileri ve yapısal süreçleri belirlemek için kullanılabilmektedir (2).

\section{Hemşirelik eğitiminde müfredat programları}

Müfredat, belirli bir okul veya programdaki öğrencilerin bilgi ve anlayış kazanmaları, becerilerini geliştirmeleri ve tutumları, takdirlerini ve değerlerini değiştirdikleri içerik ve süreçleri ifade eder (11). Müfredat, "belirli bir eğitim programının sunulması için felsefi temelleri, hedefleri ve kılavuzları sağlayan resmi bir çalışma planı" olarak da tanımlanmaktadır. Müfredat, istenen sonuçlara ulaşılmasını kolaylaştıran tutarlı 
bir çalışma programının sunulması için kritik olan bilgi, beceri, değer ve inançları kavramsallaştırmak ve organize etmeyi sağlamaktadır (5). Bir eğitim kurumu müfredatı daha önceden belirlediği hedeflere ya da sonuçlara ulaşmak için kullanılabileceği gibi aynı zamanda bilgi, beceri, düşünce ve değerlerin bir kavramsal çerçeve içinde sunulması amacı ile de kullanabilir (2). Bir hemşirelik eğitim kurumunun müfredatı genellikle o kurumun felsefe ve misyon ifadelerini içermekte; kurumun örgütsel ya da kavramsal çerçevesini tanımlamakta, derslerin ana hatlarını, eğitim faaliyetlerini ve değerlendirme yöntemlerini oluşturmaktadır $(2,5)$.

Hemşirelik eğitim müfredatı geliştirilirken iki alanın göz önünde bulundurulması önerilmektedir $(4,5)$. Bunlardan birincisi müfredatta hangi kavramlar ele alınacak? İkincisi ise kavramların tanıtımı ve aralarındaki ilişkinin tasvirinde yapı, dizilim ya da sıralama nasıl olacak? Müfredat programında ana kavramların her birinin tanımlanması ve kavramlar arasındaki ilişkinin ayrıntılı olarak açıklanması tavsiye edilmektedir. Ek olarak öğrenilecek kavramların kavramsal özellikleri ve düzenlenen içeriğin sıralamasının da mantıksal olarak tutarlı olması tavsiye edilmektedir $(4,5)$.

Dillard ve Siktberg (11) bir müfredat içeriğinin bileşenlerini;

- Tanımlanmış felsefe ve misyon ifadesi,

- Eğitim programın kavramsal çerçevesi,

- Eğitimden beklenen çıktılar; Yetkinlikler kazanılmış mı? Hedeflere ulaşılmış mı?

- Özgül bir içerik,

- Öğrenmeyi kolaylaştıran eğitim faaliyetleri ve deneyimleri,

- Eğitim çıktılarını değerlendiren araçlar olarak bildirilmiştir.

Literatürde birçok hemşirelik programının müfredatının 1949 yılında yayımlanan Tyler Müfredat Geliştirme Modeli’ne dayandığı belirtilmektedir $(2,5,12)$. Tyler Modeli'nin hemşirelik müfredatına dahil edilmesinin 1950'lerde başladığ 1 ve 1960'lar ve 1970’ler boyunca devam ettiği bildirilmektedir. Bu yıllarda Tyler'ın modeli hemşirelikte, eğitim, diploma programları, önlisans ve lisans derecelerinde tek müfredat programı olarak kullanılmıştır. Tyler Modeli, etkinlik, verimlilik ve öngörülebilirlik değerlerine sahiptir ve bireyselliği ve rekabeti 
vurgular. Tyler'ın modeli hemşirelik

komisyonlarını etkileyerek hemşirelik müfredatı üzerinde etkili olmuştur. Eyalet komisyonları hemşirelik programları ve müfredatı ile ilgili kuralları bu modele göre belirlemişlerdir $(2,5)$. Ayrıca, Tyler Modeli'nin sadece hemşirelik müfredatı ve hemşirelik eğitimini değil, akreditasyon sürecini de doğrudan etkilediği belirtilmektedir (2).

\section{Hemşirelik Eğitiminde Kuram ve Model}

\section{Kullanımı Örnekleri}

Hemşirelik kuram ve modellerindeki gelişmelerden eğitim programları da etkilenmiştir. Hemşirelik kuram ve modellerindeki gelişmeler hemşirelik müfredat programlarına da yansımıştır $(5,13,14)$. Kavramsal çerçevenin bir parçası olarak yaygın olarak kullanılan ve en çok ele alınan hemşirelik kuramcıları arasında Orem, Roy, Watson, Neuman, Banner yer almaktadır (4). Orem'in Öz-Bakım Yetersizliği Kuramı, birçok hemşirelik okulunda hemşirelik eğitimi müfredat programlarının oluşturulmasında temel olarak kullanılmaktadır. Georgetown Üniversitesi Hemşirelik Okulunun ilk yıllarından itibaren öğretilmektedir (1,15). Günümüzde hemşirelik eğitiminde kuram ve modeller bazı hemşirelik okullarında etkin olarak kullanılmaktadır. Örneğin, Kaliforniya Eyaleti'nde Mount Saint Mary's Üniversitesi Hemşirelik Bilim Lisans (BSN) Programı vizyon ve misyonunu Roy'un Adaptasyon Modeli'ne dayandırdığgnı bildirmektedir (16).

Başka bir örnek olarak Amerika'daki Tennessee Chattanooga Üniversitesi Hemşirelik Okulu verilebilir. Okul felsefe ve programını Orem'in ÖzBakım Eksikliği Kuramı'na temellendirdiğini belirtmektedir. Okulun felsefesi; insan, toplum, çevre, sağlık, hemşire/hemşirelik, öğretme ve öğrenme, inançlar ve değerler kavramlarından oluşmaktadır (17). Ayrıca, İnsan Bakım Modeli'nin, Colorado Üniversitesi'nde doktora programının müfredatının temelinde ve diğer hemşirelik eğitimi programlarında ABD'de ve Kanada'da kullanıldığı da bildirilmektedir (15) ancak ülkemizde eğitim kurumlarında temel hemşirelik eğitim müfredatının lisans ve lisans üstü programlarında hemşirelik kuram ve modellerine temellendirilmediği görülmektedir. Kuram ve model kullanılarak yapılan lisansüstü tezlerin incelendiği çalışmada da çoğunlukla doktora tezi 
(\%88.5), oldukça az oranda da yüksek lisans tezi (\%11.5) olduğu görülmektedir. Ülkemizde hemşirelik kuram ve modelleri ile ilgili verilen derslerin doktora eğitiminde verilmesiyle bağlantılı olabileceği düşünülmektedir. Hemşirelik lisansüstü eğitimde öğrencilere kuram/model kullanımı konusunda bakış açısı kazandırılması, için teori ve modellerle ilgili derslerin her ders döneminde ve bilim dalları derslerine entegre edilerek, olgular üzerinden işlenerek daha somut ve anlaşılır hale getirilmesi önerilmektedir (18).

\section{Hemşirelik Eğitiminde Kuram ve Model}

\section{Kullanımı ile İlgili Yapılmış Çalışmalar}

Hall (13) yaptığı çalışmada, 144 hemşirelik okulunu müfredat ders programları yönünden incelemiş ve bu okulların \%41'inin bir ya da birden fazla hemşirelik kuram ve modeline göre müfredat ders programlarını temellendirdiğini saptamıştır. Araştırmasında, müfredat ders programlarının en sık Orem, Rogers, Levine, King, Roy ve Johnson'a ait hemşirelik kuram ve modellerine dayandırıldı bildirmektedir.

McEven (4), Amerika'da Hemşirelik Akreditasyon Komitesi Ulusal Ligi ile akredite hemşirelik lisans okulları arasından rastgele örnekleme yöntemiyle seçtiği 300 hemşirelik lisans eğitimi veren okul arasından çalışmaya katılan 160 okulu kavramsal çerçevesi ve müfredat programları yönünden incelemiş, okulların \%33'ünün programlarının kavramsal çerçevesinde hemşirelik teorilerini temel bir bileşen olarak bildirdiklerini tespit etmiştir. Müfredatta en sık kullanılan kuramların Orem'in Öz-Bakım ve Roy'un Adaptasyon Kuramı olduğunu bildirmiştir.

Berbiglia (14) Orem'in Öz-Bakım Eksikliği Kuramı'nın hemşirelik eğitiminde kavramsal çerçeve oluşturmada kullanımını araştırdığ 1 çalışmasında, Anderson Üniversitesi Hemşirelik Okulu, Southern Üniversitesi Baton Rouge Hemşirelik Okulu ve Tennessee Chattanooga Üniversitesi Hemşirelik Okulunda Öz-Bakım Eksikliği Kuramı'nın müfredatın tüm bileşenlerinde kullanıldığını, bu okullarda hemşirelik bakım aktivitelerinin, eğitim ve uygulamaların amacının öz bakımı sürdürmek ve öz bakım eksikliğini önlemek olduğunu bildirmiştir.

Secrest (19), Orem'in Öz-Bakım Eksikliği Kuramı'na odaklanan müfredatlarında revizyon 
sağlama amacına yönelik olarak araç geliştirme sürecini ve fakültenin rolünü tanımlamıştır.

Beckman ve ark. (20), Neuman'ın Sistem Modeli'ni kullanarak fakültelerinde ön lisans programından lisans programına dönüştürülme sürecinde hemşirelik programının müfredat çerçevesini tartışmışlardır.

Hartweg (21) çalışmasında, Amerika Birleşik Devletleri'nde Bakalorya programlarında hemşirelik teorisi kullanımını $\operatorname{araştırdı̆̆~}$ çalışmalarında 286 okulun 171 tanesinde müfredatlarında hemşirelik teorisinin kullanıldığgnı bildirmektedir.

Dowd (22), Konfor Kuramı'nın hemşirelik eğitiminde, öğrencilerin tanılama ve bakım planlarını düzenlemede kolaylıkla kullanabileceklerini bildirmektedir.

Watson (23), İnsan Bakım Modeli'nin eğitim, uygulama ve yönetimde etik bir rehber olarak kullanılabileceğini belirtmektedir. Sawatzky ve ark. (24) İnsan Bakım Modeli’nin hasta bakımı ile birlikte hemşirelik eğitiminde de kullanılabileceğini, böyle bir etkileşimle öğrencinin önce kendisinin bu anı yaşayacağı ve hastasına yansıtacağını savunmaktadır. Güçlü bir bakım etiğine sahip eğitmenin, öğrenci için iyi bir rol model olduğu bildirmektedir (24).

Leininger'in teorisi lisans mezunu hemşireler arasında kültürel yeterliliği geliştirmek için oldukça önemli kabul edilmektedir. 1980’lerin sonlarında, Birleşik Devletler'de dört yüksek lisans ve doktora programında Leininger'in teorisine temellenen transkültürel hemşirelik kursları ve kılavuzlu saha çalışmaları başlatıldığ bildirilmektedir (25).

Hemşirelik eğitiminde kuram ve model kullanılmasının önemine vurgu yapan Drummond ve Oaks (26)'ın ve Yancey (27)'in araştırmaları da dikkat çekicidir. Çalışmalar, Parse'ın İnsan Olma Kuramı'nın hemşirelik eğitim ve uygulamalarında kullanımıyla ilgili güzel örnekler sunmaktadır.

\section{SONUÇ}

Hemşirelik kuram ve modellerinin birincil amacı hemşirelik biliminin gelişmesini sağlamaktır. Hemşirelik eğitiminde kuram ve model kullanımı hemşirelerin ortak bir dile sahip olmasını sağlayacaktır. Öğrencilerin hemşireliğin ne olduğunu ve hemşirelik bakımının neyi gerektirdiğini tam olarak anlamalarını sağlamak için lisans düzeyinde müfredata uyumlu hemşirelik 
kuram ve modellerinin kullanılması gerekliliği

dikkat çekmektedir. Kullanılacak kavram ve

modeller farklı hemşirelik dünya görüşünü

kapsamalı, öğrenmeyi teşvik etmeli, verimli ve

kapsamlı olmalıdır. Sonuç olarak, hemşirelik eğitim programlarının sağlık bakım gereksinimleri ve beklentiler doğrultusunda gözden geçirilmesi, uygulanmakta olan Tıbbi Model yerine hemşirelik bakımını ve hemşirelik kuramlarını temel alan yeni bir eğitim müfredatına temellendirilmesi, eğitimde inovasyon ve akreditasyon çalışmalarının sürdürülmesi önerilmektedir.

\section{KAYNAKLAR}

1. Velioğlu P. Hemşirelikte kuramsal ve kavramsal çalışmaların tarihsel gelişim süreci. In: Hemşirelikte Kavram ve Kuramlar. İstanbul: Akademi Basın ve Yayıncılık; 2012. p.364-394.

2. Wills EM, McEven M. Application of theory in nursing education. In: Theoretical basis for nursing. London: Lippincott Williams \& Wilkins; 2011. p.440-458.

3. Phillips JM, Resnick J, Boni MS, Bradley P, Grady JL, Ruland J, Stuever NL. Voices of innovation: Building a model for curriculum transformation. International Journal of Nursing Education Scholarship. 2013; 10(1):1-7.

4. McEwen M, Wills EM. Theoretical basis for nursing. Philadeplhia: Lippincott Williams \& Wilkins Wolters Kluwer; 2014. p.412-29.

5. McCrae N. Whither nursing models? The value of nursing theory in the context of evidence-based practice and multidisciplinary health care. Journal of Advanced Nursing. 2011; 68(1):222-229.

6. Şanlı D, Platin N. Biyomedikal modelin hemşireliğe etkisi. Journal of Human Sciences. 2015; 12(2):897-908.

7. Meleis AI. On the way to theoretical nursing: Stages and milestones. In: Theoritical nursing: Development \& Progress. London: Lippincott Williams \& Wilkins; 2007. p.78-108.

8. Barnum BS. Nursing theory: Analysis, application, evaluation. Philadelphia: Lippincott. Williams \& Wilkins; 1998.

9. Ocakçı AF, Ecevit Alpar Ș. Hemşirelik kavram, kuram ve modelleri. In: Hemşirelikte kavram, kuram ve model örnekleri. İstanbul: İstanbul Tip Kitabevi; 2013. p.1-13.

10. Dillard N, Siktberg L. Curriculum development: An overview. In: Teaching in Nursing E-Book: A Guide for Faculty; 2013. p.76.

11. Koç Z, Kızıltepe KS, Cınarlı T, Şener A. Hemșirelik uygulamalarında, araştırmalarında, yönetiminde ve eğitiminde kuramların kullanımı. Hemşirelikte Eğitim ve Araștırma Dergisi. 2017; 14 (1):62-72.

12. Hall KV. Current trends in the use of conceptual frameworks in nursing education. Journal of Nursing Education. 1979; 18(4):26-31.

13. Tadaura H, Sato A, Ueda E, Ishigaki H, Saita T, Kikuchi T. Connecting nursing theory with practice through education based on Self-Care Deficit Nursing Theory (SCDNT) and utilization of nursing practice. Self-Care, Dependent-Care \& Nursing. 2014; 21(1):27-29.
14. Berbiglia VA. The Self-Care Deficit Nursing Theory as a curriculum conceptual framework in Baccalaureate Education. Nursing Science Quarterly. 2011; 24(2):137-145.

15. Fitzpatrick JJ, Whall AL. Conceptual models of nursing. In: Analysis and application. Canada: Phoenix Color Company; 2005. p.1-348.

16. Mount Saint Mary's University [Internet]. Nursing Undergraduate Bachelor Programs; 2020 Jun 06 [cited 2020 Jun 14]; Available from: https://www.msmu.edu/undergraduate-bachelor-programs/nursing/

17. The University of Tennessee Chattanooga, School of Nursing [Internet]. Philosophy; 2020 Jun 06 [cited 2020 Jun 14]; Available from: https://www.utc.edu/nursing/about/philosophy.php

18. Şahin $\mathrm{G}$, İlkim Buldak $\mathrm{C}$, Kaya $\mathrm{V}$, Güvenç $\mathrm{G}$, İyigün $\mathrm{E}$. The examination of the graduate studies performed by using the theory and model in the nursing field at Turkey: A systematic review. Journal of Education and Research in Nursing. 2020; 17(2):170-179.

19. Secrest J. The role of tool development in Orem-Based Curriculum. Self- Care Depend Care Nurs. 2008; 16(2):25-33.

20. Beckman SJ, Boxley-Harges SL, Kaskel BL. Experience informs Spanning three decades with the Neuman Systems Model. Nursing Science Quarterly. 2012; 25(4):341-346.

21. Hartweg DL. Dorothea Orem's Self-Care Deficit Nursing Theory. In Kelley M, editor. Nursing theories and nursing practice. Philadeplhia: F.A. Davis Company; 2015; p.105-132.

22. Dowd TL. Teoria del confort: Katharine Kolcaba. In: Tomey AM, Alligood MR, editors. Modelosy teorias em enfermería. Madrid: Elsevier; 2005. p.430-42.

23. Watson J. Context for theory development. In: Nursing: Human science and human care. Sudbury: Jones and Barlett Publishers; 2007. p.1-12.

24. Sawatzky JV, Enns CA, Ashcroft TJ, Davis PL, Harder BN. Teaching excellence in nursing education: A caring framework, Journal of Professional Nursing. 2009; 25(5):260-266.

25. Alligood MR. Philosophies, models, and theories: critical thinking structures. In: Alligood MR, Tomey AM. editors. Nursing theory: Utilization \& application. Newyork: Mosby Elsevier; 2006.

26. Drummond S, Oaks G. A curriculum founded on human becoming: Educational endeavoring. Nursing Science Quarterly. 2015; 29(1):2529.

27. Yancey NR. Why teach nursing theory? Nursing Science Quarterly. 2015; 28(4):274-278. 